\title{
perifèria
}

Número 8, junio 2008

www.periferia.name

\section{Antropología. Teorías de la Cultura, Métodos y Técnicas}

Isabel Gentil García - Universidad Complutense de Madrid ${ }^{1}$

Tomas Calvo Buezas y Domingo Barbolla Camarero. Antropología. Teorías de la Cultura, Métodos y Técnicas (2006). Badajoz: Editorial @becedario

Antropología Social y Cultural, disciplina que busca entender la condición humana, podemos sospechar que es tan antigua como los humanos, porque desde que habitamos este planeta nos hemos formulado las mismas preguntas ¿quiénes somos? ¿Qué hacemos aquí? ¿De dónde venimos? ¿Dónde vamos? Para saber más de nosotros mismos, desde aquella remota primigenia, hemos utilizado la misma estrategia: observarnos y compararnos con los Otros, con los que creíamos diferentes por el hecho de vivir en diferente territorio, o hablar diferente lengua. Así lo refleja uno de los autores del presente libro, el Catedrático Emérito de Antropología Social Tomás Calvo Buezas: “Antropología Social y Cultural, reciente disciplina académica y <ciencia> social moderna desde la llustración, es, sin embargo, un saber antiguo como el hombre: conocer quienes somos <nosotros>, mirándonos en el espejo de los <otros>. Siempre ha existido en todos los pueblos un intento de clasificar, contrastar y comparar nuestras costumbres y formas de vida con las de nuestros vecinos, es decir, estudiar nuestras culturas frente a las extrañas. Este impulso y pasión humana de conocernos y clasificarnos frente a los otros, se ha manifestado y desarrollado en muy distintas formas de conocimiento, según los tiempos, condiciones tecnoeconómicas y tecnológicas, según sociedades, culturas y religiones."

\footnotetext{
${ }^{1}$ I sabel Gentil García: Doctora en Antropología Social y Cultural. Escuela U. Enfermería, Fisioterapia y Podología (Facultad de Medicina 3a planta, Madrid 28040). Correo electrónico: isagen@enf.ucm.es
} 


\section{perifèria}

Número 8, junio 2008

www. periferia. name

Este libro consta de seis partes. Las cinco primeras escritas por el Catedrático Emérito de Antropología Social de la Universidad Complutense de Madrid, Tomás Calvo Buezas, son el resultado sensato y reflexivo de toda una vida dedicada a la docencia e investigación en el campo de la Antropología Social y Cultural. El doctor Calvo Buezas como director del Centro de Estudios sobre Migraciones y Racismo (CEMIRA) de la UCM, ha realizado numerosas investigaciones sobre minorías, gitanos, distintas etnias americanas, inmigrantes hispanos en EE.UU. e inmigrantes en España. Dieciocho libros publicados y numerosos artículos avalan su actividad intelectual.

Estas cinco primeras partes comienzan con una introducción en la que significativamente el autor subtitula ¿qué es antropología? En los 20 capítulos siguientes va dando respuesta a la pregunta que inicia el libro. Nos encontramos con 20 capítulos de aportación teórica y epistemológica sobre cómo se ha construido el conocimiento en la disciplina antropológica. La sexta y última parte, escrita por el Profesor Titular de Antropología Social en la Universidad de Extremadura, Domingo Barbolla Camarero, que fue alumno del anterior y miembro del CEMIRA, describe las técnicas de investigación en antropología, dejando abierta la puerta para que el lector estudioso pueda seguir construyendo el camino de futuro.

Este Manual de Antropología ofrece una serie de singularidades. Una de ellas es que el catedrático Calvo Buezas entiende la construcción histórica del conocimiento antropológico en diálogo constante con la Historia, la Filosofía, la Hermenéutica, la Arqueología, la Lingüística y la Antropología Física. Para él, el saber antropológico es una acumulación desde los clásicos griegos y romanos, de San Agustín, de los científicos naturales del Renacimiento, de los pensadores de la Ilustración, "así se fueron constituyendo históricamente unas formas diferenciadas de conocimiento, con distintas teorías sobre las culturas humanas y diversas metodologías para compararlas e investigarlas." Defiende que la construcción del saber antropológico no puede desgajarse de otras disciplinas que tratan sobre lo humano. También de autores más recientes que tanto han contribuido a modificar perspectivas de enfoque como K. Marx y F. Engels, S. Freud, F.G. Bayley, M. Eliade, E. Cassirer, R. 


\section{perifèria}

\section{Número 8, junio 2008}

www.periferia. name

Nisbert, J. Bury. Presenta una argumentación clarificadora en relación a la necesidad de establecer un paralelismo entre antropología y otros paradigmas. La argumentación es sostenida con numerosas citas que enriquecen permanentemente el texto.

Otra singularidad es considerar que "la Sociología es nuestro ancestro más similar y cercano". Por ello, sigue diciendo el profesor Calvo Buezas, "la opción personal por el diálogo constante con la Sociología". Esta es la razón de que aparezcan reflejados numerosos párrafos de textos de obras de sociólogos, desde los grandes clásicos como E. Durkheim o A. Compte hasta obras de sociólogos actuales como, M. Foucault o P. Bourdieu y los sociólogos españoles, C. Moya, L. Seara, S. del Campo, J.A. Maravall, entre otros. Otra singularidad derivada de todo lo anterior, es que contextualiza el conocimiento antropológico a nivel internacional, lo que permite comprenderlo mejor.

Aunque quizá la singularidad mayor radica en combinar todo lo anterior, es decir esa visión pluralista y universal de la construcción del saber antropológico con un reconocimiento de lo familiar y cercano al hacer referencia al nacimiento de la disciplina antropológica. Se pregunta el profesor Tomás Calvo Buezas "la antropología Cultural ¿nació en las Indias, hablando castellano-náhuatl-quechua, y no hablando inglés en Europa y USA?" y ésta pregunta da título a todo un capítulo. Donde va respondiendo y matizando, "los escritos de Indias de los siglos XVI y XVII son propios del quehacer antropológico" porque, sigue diciendo, "forman un archivo documental bibliográfico cuyo telón de fondo son otros modos de vida, otras costumbres, otras instituciones, otros dioses, en definitiva otras culturas". Insiste en que deberían darse más importancia a los escritos del siglo XVI por sus contribuciones precoces a lo que sería en el futuro los paradigmas de la Antropología. Quizá esta singularidad sea fruto de su estancia de varios años en América. En sus universidades, primero como alumno y después como profesor, y en sus investigaciones realizando extenso trabajo de campo con chicanos, puertorriqueños, indios cunas e indios huicholes. 


\section{perifèria}

Número 8, junio 2008

www. periferia. name

Todas las singularidades señaladas no entran en contradicción con que el presente libro es a la vez un auténtico Manual de Antropología en formato clásico académico. En parte, porque el material base del mismo es la Memoria para la oposición a Cátedra en Antropología Social de Tomás Calvo Buezas, y a la de Profesor Titular de Antropología Social de Domingo Barbolla. En parte porque los autores así lo han buscado para que el libro sea un autentico manual pedagógico y didáctico. Lo han logrado.

La estructura del Manual es la siguiente. En su primera parte elabora la construcción histórica social de la antropología, tomando las fuentes de los pensadores que han construido la Cultura Occidental, desde la antigüedad hasta nuestros días. En realidad el saber humanista científico es uno, aunque le añadamos adjetivos diferentes según la disciplina en que desarrollemos nuestra actividad profesional: antropología, filosofía, sociología, psicología social, historia, lingüística u otras. La segunda parte está dedicada a los diferentes paradigmas de la considerada antropología científica moderna: evolucionismo, difusionismo, particularismo histórico. La tercera parte analiza los viejos y nuevos paradigmas: neomarxismo, neoevolucionismo, cambio, personalidad y lenguaje, ecología cultural. Aquí hay un sobresaliente capítulo dedicado a migraciones, minorías y aculturacuración, donde se estudian, entre otras cuestiones, "USA: <melting pot> de etnias. <meltinng pot> de estudios" y "desarrollismo, cultura de la pobreza y lucha de clases".

La cuarta parte aborda los paradigmas funcionalismo, estructuralismo, antropología cognitiva y la antropología posmoderna. Todo ello es apoyado por el análisis de numerosos textos de antropólogos, desde los primeros, Tylor, Morgan, Frazer hasta Lisón Tolosana y Lèvy-Strauss, pasando por otros autores imprescindibles y presentes en cualquier Manual de Antropología. A lo largo de los capítulos se van interpretando, de forma excelente, los diferentes campos de estudio antropológico: instituciones, migraciones, simbolismo etc. La quinta parte está dedicada a una extensa y amplia exposición sobre metodología científica e investigación en antropología. Dedicando especial atención a la antropología aplicada. “¿Es posible la antropología en sociedades complejas?" es uno los temas abordados. La sexta 


\section{perifèria}

\section{Número 8, junio 2008}

www. periferia. name

parte, como dijimos, describe y analiza las distintas técnicas de investigación utilizadas en antropología, desde las clásicas: observación participante, historias de vida, redes sociales, grupos de discusión, cuestionarios, análisis del contenido, insertas todas ellas en los marcos teóricos, a lo más actual como la ciberantropología. Termina mostrando cómo se debe redactar un texto antropológico.

Se complementa con una extensísima bibliografía que contextualiza la cantidad de citas e información que han ido apareciendo a lo largo del manual.

Con todo ello, este libro se convierte en un completo manual que ofrece lecturas a muy diversos niveles. Nos da claves para entender que el saber antropológico no sólo tiene pasado, también presente, ya que los problemas que plantea la compleja sociedad actual pueden y deben ser analizados con un enfoque cultural. $Y$ tiene futuro porque los retos derivados de un mundo necesariamente cada vez más global, de un planeta en riesgo por ciertas actividades humanas, hace necesario la participación y responsabilidad de los ciudadanos de todo el planeta y el enfoque antropológico al estudiar lo más profundo de los humanos, parece imprescindible para ayudarnos en la construcción de una convivencia en paz.

Recordando que precisamente porque los autores entienden la Antropología Social y Cultural con un concepto multidisciplinar y multiparadigmático es por lo que este Manual es útil para profesionales y estudiantes no sólo de Antropología, sino también de Sociología, Historia, Psicología, Filosofía, Ciencias de la Educación y Ciencias de la Salud. Es decir todos aquellos que por su actividad profesional estén en contacto directo con otros seres humanos, que tenga responsabilidades y toma de decisiones que afectan a otros seres humanos y que por tanto necesiten profundizar en el conocimiento sobre los otros. 